\title{
New metabolic and endocrine approaches in pediatrics
}

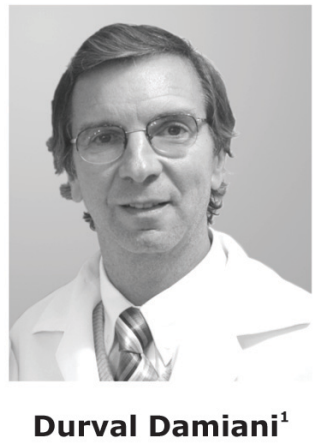

People say that a specialist is someone who learns increasingly more about less. This specialist will eventually reach the state of the art of knowing EVERYTHING about NOTHING!

Despite the exaggeration, we live in a time in which the knowledge of each medical specialty has reached startling proportions. Keeping up to date has become a major task even for specialists, and the situation is no different in the fields of pediatric endocrinology and pediatric intensive care. Nevertheless, this degree of specialization has brought along more precise diagnostic tools and much more rational treatment interventions.

General pediatricians may interpret the emphasis on specialization as a sign that their role has become less important, since they do not specialize in any specific area and rather act as "general practitioners" for children. In fact, the success of treatment depends to a great extent on the precision with which general pediatricians practice, since they have the mission - far from easy - of detecting anomalies and referring the patient to the right specialist, with whom they must then work. A patient is a "whole" being, and not just a thyroid, pancreas or adrenal gland. The success of the specialist depends on the general equilibrium of the patient. Team work

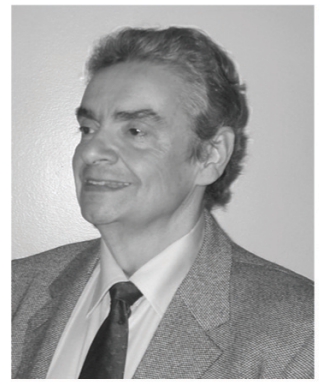

\section{Pedro Celiny Ramos Garcia²}

is no doubt the best way to ensure that the patient will be provided the best in diagnosis and treatment.

In the present issue, the Jornal de Pediatria seeks to outline an overview of some aspects of pediatric endocrinology and intensive care in order that general pediatricians may direct their actions more appropriately.

To fulfill the mission of this Supplement, we had the difficult task of choosing subjects that are relevant for all pediatricians. Our strategy was to cover everything from the new frontiers in the endocrine and metabolic management of children in intensive care to the first evaluation at the doctor's office. Controversial topics in the management of the critically ill child, such as glycemic control and insulin therapy for sepsis, vasopressin for shock, diagnosis of adrenal failure and intensive management of diabetic ketoacidosis have all been included. In this way we chose to deal with the question of corticoid therapy, so familiar to pediatricians, and the issue of short stature, a cause of complaint for many children and parents in an era in which height is overvalued. On the other hand, who, practicing general pediatrics, has not faced a diabetic child? In this issue, we are reminded that not all diabetic children have type 1 diabetes.

1. Professor livre-docente. Chefe, Unidade de Endocrinologia Pediátrica, Instituto da Criança, Hospital das Clínicas, Faculdade de Medicina, Universidade de São Paulo (USP), São Paulo, SP, Brazil.

2. Doutor. Professor adjunto, Departamento de Pediatria, Curso de Pós-Graduação em Pediatria e Saúde da Criança, Faculdade de Medicina, Pontifícia Universidade Católica do Rio Grande do Sul (PUCRS), Porto Alegre, RS, Brazil. Médico Chefe, Serviço de Terapia Intensiva Pediátrica, Hospital São Lucas da PUCRS, Porto Alegre, RS, Brazil.

Suggested citation: Damiani D, Garcia PC. New metabolic and endocrine approaches in pediatrics. J Pediatr (Rio J). 2007;83(5 Suppl):S117-118.

doi 10.2223/JPED.1717 
5118

The first physician to deal with a child with ambiguous genitalia is the pediatrician, not the endocrinologist. Clear directives concerning this problem are essential to ensure an effective psychosocial adaptation for the patient and the family.

We live in a world which is getting heavier day by day, and knowing about "adipose tissue" has become a must. It has gone from being a mere fat deposit to being the most complete endocrine organ we have, and so it is important to get to know it in a little more detail.

We also discuss the metabolic syndrome, which, with all its implications for cardiovascular risk, is becoming increasingly more common, following the growing trend of obesity.
New metabolic and endocrine approaches - Damiani D \& Garcia PC

Congenital hypothyroidism is being detected early thanks to neonatal screening. It is the general pediatrician who will receive the first test results, and thus s/he must be prepared to interpret them appropriately.

We have received the invaluable support of highly competent professionals, who have managed to transform dry subjects into extremely engaging discussions, without losing the necessary depth. We hope that the content of this Supplement to the Jornal de Pediatria will become an important and useful reference for its target public, i.e. general pediatricians. 